\title{
Comparing the Ottawa Emergency Department Shift Observation Tool (O-EDShOT) to the traditional daily encounter card: measuring the quality of documented assessments
}

\author{
Kaitlin Endres ${ }^{1} \cdot$ Nancy Dudek ${ }^{2}$. Meghan McConnell ${ }^{3,4}$ - Warren J. Cheung ${ }^{5}$
}

Received: 10 August 2020 / Accepted: 14 December 2020 / Published online: 29 January 2021

() The Author(s), under exclusive licence to Canadian Association of Emergency Physicians (CAEP)/ Association Canadienne de Médecine d'Urgence (ACMU) 2021

\begin{abstract}
Objectives The Ottawa Emergency Department Shift Observation Tool (O-EDShOT) is a workplace-based assessment designed to assess a trainee's performance across an entire shift. It was developed in response to validity concerns with traditional end-of-shift workplace-based assessments, such as the daily encounter card. The O-EDShOT previously demonstrated strong psychometric characteristics; however, it remains unknown whether the O-EDShOT facilitates measurable improvements in the quality of documented assessments compared to daily encounter cards.

Methods Three randomly selected daily encounter cards and three O-EDShOTs completed by 24 faculty were scored by two raters using the Completed Clinical Evaluation Report Rating (CCERR), a previously published 9-item quantitative measure of the quality of a completed workplace-based assessment. Automated-CCERR (A-CCERR) scores, which do not require raters, were also calculated. Paired sample $t$ tests were conducted to compare the quality of assessments between O-EDShOTs and DECs as measured by the CCERR and A-CCERR.

Results CCERR scores were significantly higher for O-EDShOTs (mean $(\mathrm{SD})=25.6(2.6))$ compared to daily encounter cards $(21.5(3.9) ; t(23)=5.2, p<0.001, \mathrm{~d}=1.1)$. A-CCERR scores were also significantly higher for O-EDShOTs $(\operatorname{mean}(\mathrm{SD})=18.5(1.6))$ than for daily encounter cards $(15.5(1.2) ; t(24)=8.4, p<0.001)$. CCERR items 1,4 and 9 were rated significantly higher for O-EDShOTs compared to daily encounter cards.

Conclusions The O-EDShOT yields higher quality documented assessments when compared to the traditional end-of-shift daily encounter card. Our results provide additional validity evidence for the O-EDShOT as an assessment tool for capturing trainee on-shift performance that can be used as a stimulus for actionable feedback and as a source for high-quality workplacebased assessment data to inform decisions about emergency medicine trainee progress and promotion.
\end{abstract}

Keywords Emergency medicine $\cdot$ Trainee assessment $\cdot$ Assessment quality $\cdot$ Entrustability scales

Supplementary Information The online version contains supplementary material available at https://doi.org/10.1007/s4367 8-020-00070-y.

Warren J. Cheung

wcheung@toh.ca

1 Faculty of Medicine, University of Ottawa, Ottawa, Canada

2 Division of Physical Medicine and Rehabilitation, Department of Medicine, The Ottawa Hospital, University of Ottawa, Ottawa, ON, Canada

3 Department of Innovation in Medication Education (DIME), University of Ottawa, Ottawa, Canada
4 Department of Anesthesiology and Pain Medicine, University of Ottawa, Ottawa, Canada

5 Department of Emergency Medicine, University of Ottawa, The Ottawa Hospital - Civic Campus, 1053 Carling Ave, Room F660b, Ottawa, ON K1Y 4E9, Canada 


\section{Résumé}

Objectifs L'outil d'observation des quarts de travail des services d'urgence d'Ottawa (O-EDShOT) est une évaluation en milieu de travail conçue pour évaluer la performance d'un stagiaire pendant tout un quart de travail. Il a été développé en réponse à des problèmes de validité avec les évaluations traditionnelles en milieu de travail de fin de quart de travail, comme la fiche de rencontre quotidienne (DEC). Le O-EDShOT avait préalablement démontré de fortes caractéristiques psychométriques; cependant, on ignore toujours si l'O-EDShOT facilite des améliorations mesurables de la qualité des évaluations documentées par rapport aux fiches de rencontre quotidiennes.

Méthodes Trois fiches de rencontre quotidiennes sélectionnées au hasard et trois O-EDShOT complétés par 24 membres du corps professoral ont été marqués par deux évaluateurs à l'aide de Completed Clinical Evaluation Report Rating (CCERR), une mesure quantitative en 9 points publiée précédemment de la qualité d'une évaluation en milieu de travail réalisée. Les scores du CCERR automatisé (A-CCERR), qui ne nécessitent pas d'évaluateur, ont également été calculés. Des tests t d'échantillons appariés ont été effectués pour comparer la qualité des évaluations entre les O-EDShOT et les DEC, telle que mesurée par le CCERR et l'A-CCERR.

Résultats Les scores CCERR étaient significativement plus élevés pour les O-EDShOT (moyenne $(\mathrm{ET})=25,6(2,6)$ ) par rapport aux fiches de rencontre quotidiennes $(21,5(3,9) ; \mathrm{t}(23)=5,2, \mathrm{p}<0,001, \mathrm{~d}=1,1)$. Les scores A-CCERR étaient également significativement plus élevés pour les O-EDShOT (moyenne $(\mathrm{ET})=18,5(1,6)$ ) que pour les fiches de rencontre quotidiennes $(15,5(1,2) ; \mathrm{t}(24)=8,4, \mathrm{p}<0,001)$. Les points 1,4 et 9 du CCERR ont été notés beaucoup plus haut pour les $\mathrm{O}-\mathrm{EDShOT}$ que pour les fiches de rencontre quotidiennes.

Conclusions L'O-EDShOT produit des évaluations documentées de meilleure qualité par rapport à la traditionnelle fiche de rencontre quotidienne de fin de quart de travail. Nos résultats fournissent des preuves de validité supplémentaires pour l'OEDShOT en tant qu'outil d'évaluation pour saisir les performances des stagiaires en poste qui peuvent être utilisés comme stimulus pour une rétroaction exploitable, et comme source de données d'évaluation de haute qualité en milieu de travail pour notifier les décisions sur la progression et promotion des stagiaires en médecine d'urgence.

\section{Clinician's capsule}

What is known about the topic?

The Ottawa Emergency Department Shift Observation Tool (O-EDShOT) is a workplace-based assessment that has previously demonstrated strong psychometric characteristics.

\section{What did this study ask?}

Whether the O-EDShOT facilitates measurable improvements in the quality of documented assessments compared to the traditional daily encounter card.

\section{What did this study find?}

O-EDShOTs yield higher quality documented assessments compared to traditional daily encounter cards as measured by the Completed Clinical Evaluation Report Rating (CCERR).

\section{Why does this study matter to clinicians?}

The O-EDShOT has value for providing quality assessment information that drives actionable feedback and informs high-stakes decisions about trainee progress/promotion.

\section{Introduction}

With the transition to competency-based medical education occurring for all post-graduate medical education programs

by 2022 , workplace-based assessments are being increasingly incorporated into systems of assessment [1]. A common form of workplace-based assessment in the emergency department (ED) is the end-of-shift assessment, traditionally in the form of a daily encounter card, which is intended to capture the performance of a trainee during a shift [2]. Daily encounter cards facilitate the simultaneous assessment of multiple competencies during an ED shift [2-4] and are designed to capture expert judgement of a trainee's performance after a brief supervisor-trainee interaction, thus minimizing recall bias [2-7].

Despite these benefits, evidence suggests that the quality of assessments documented on daily encounter cards are poor [2]. Bandiera and Lendrum [8] found that daily encounter cards were subject to leniency or range restriction effects wherein supervisors provided "inflated" or overly favourable assessments leading to indiscriminate ratings. Sherbino et al. [6] found that daily encounter card items were not well understood by front-line supervisors, resulting in poor reliability and questionable validity of the scores. While many other assessment tools have been developed to assess performance during an ED shift, a systematic review of the literature demonstrated a paucity of validity evidence for most of these workplace-based assessments [9]. In response, the Ottawa Emergency Department Shift Observation Tool (O-EDShOT) was developed (see online Supplemental Appendix A) [5].

The O-EDShOT is an outcomes-oriented workplacebased assessment designed to assess a trainee's ability to 
effectively manage an ED shift-a defining attribute of any emergency physician and a key outcome of residency training $[5,10,11]$. The O-EDShOT uses a rating scale that incorporates entrustment anchors that have been shown to produce more reliable ratings of performance compared to traditional anchors [5, 12-16]. Previous studies have demonstrated that the O-EDShOT is able to discriminate performance abilities between training levels and provide a reliable measure of a trainee's ability to safely run an ED shift independently. Further, preceptors and trainees perceive the O-EDShOT to be more feasible, practical, and time efficient compared to the traditional daily encounter card [5]. What remains unknown is whether the O-EDShOT provides measurable improvements in the quality of documented assessments compared to the traditional daily encounter card.

\section{Methods}

\section{Study design and time period}

This retrospective study compared the quality of documented assessments between the daily encounter card and the O-EDShOT as measured by the Completed Clinical Evaluation Report Rating (CCERR) [2, 17-21]. Daily encounter cards included in this study were completed by clinical supervisors for trainees between December 2017-May 2018 (see online Supplemental Appendix B). O-EDShOTs included were completed from July-December 2018. This study received full ethics review exemption from the Ottawa Health Science Network Research Ethics Board.

\section{Study setting and population}

This study was conducted in the Department of Emergency Medicine at the University of Ottawa, which is comprised of two tertiary care campuses of The Ottawa Hospital. Daily encounter cards and O-EDShOTs completed by clinical supervisors for trainees in the Royal College of Physicians and Surgeons of Canada Emergency Medicine (RCPSC-EM) residency program during the study period were included. The majority of faculty development in preparation for the transition to competency-based medical education occurred prior to December 2017.

\section{Measure of assessment quality}

Between January-April 2020, the CCERR was used to determine the quality of assessments documented on daily encounter cards and O-EDShOTs [2, 17]. The CCERR is a nine-item instrument designed to provide a quantitative measure of the quality of completion of an in-training evaluation report [17]. Validity evidence for CCERR scores has recently been demonstrated for end-of-shift workplace-based assessments, including high reliability and the ability to discriminate workplace-based assessments of varying quality $[2,7,20]$. Use of the CCERR does not require raters to undertake any training other than reading the instructions [17-20]. Raters in this study could not be blinded to the type of assessment (daily encounter card vs O-EDShOT) as the forms are visibly different. Therefore, the quality of daily encounter card and O-EDShOT completion was also measured using the Automated-CCERR (A-CCERR). The A-CCERR is a less resource-intensive tool that does not require raters, thus obviating the need for blinding. It provides a reliable measure of the quality of documented assessments based on word count, variability in ratings, and the proportion of comment boxes completed on the form [21].

\section{Sample size and procedures}

Based on prior studies, we estimated that 24 faculty supervisors were required to detect a 3-point difference in mean CCERR scores to achieve a power of $80 \%$ and a significance level of 5\% (two-tailed), assuming a standard deviation of $6.21[2,17]$. For each of the 24 faculty supervisors, six assessment forms ( 3 daily encounter cards and 3 O-EDShOTs) were sufficient to ensure a reliability of 0.80 (95\% confidence interval 0.75-0.84). Prior research has identified high levels of interrater reliability using the CCERR, and as such, two faculty raters scored each daily encounter card and O-EDShOT [2, 17, 21].

Daily encounter cards and O-EDShOTs were collected from the Department of Emergency Medicine electronic database by a research assistant. Based on the sample size calculation above, three daily encounter cards and three O-EDShOTs completed by 24 different faculty supervisors were randomly selected using a random number generator [22]. There was a similar proportion of residents at each training level (PGY15 ) in our sample of daily encounter cards and O-EDShOTs. All 144 assessment forms, 72 daily encounter cards and 72 O-EDShOTs, were further deidentified by a research assistant. Subsequently, two faculty raters scored each deidentified daily encounter card and O-EDShOT using the CCERR. CCERR scores were calculated by summing the scores for the 9 individual CCERR items. A-CCERR scores were calculated using the previously published formula: logarithm of the A-CCERR $=1.087+0.001$ (word count $)+0.028$ (variability in ratings) +0.069 (proportion of comments completed) [21] This provided for "blinded scores" as no raters are required for the A-CCERR.

\section{Data analysis}

Data analysis was conducted using IBM SPSS Statistics for Windows Version 26.0 (IBM Corp., Armonk, NY, USA). 
For each faculty member, mean faculty CCERR scores were calculated by collapsing across the three assessments for both daily encounter card and O-EDShOT forms. As a measure of homogeneity, item-total correlations (ITCs) were calculated for each CCERR item across the two assessment forms. Interrater reliability for the daily encounter card and O-EDShOT were then calculated using intraclass correlation coefficient (ICC) based on a two-way mixed-effects singlemeasure model [23].

We interpreted ICCs $<0.50$ to be indicative of poor interrater reliability, values between 0.50 and 0.75 to indicate moderate interrater reliability, values between 0.75 and 0.90 to indicate good interrater reliability, and values $>0.90$ to indicate excellent interrater reliability [24]. To examine the internal consistency of CCERR items for daily encounter cards and O-EDShOTs, mean CCERR item ratings were calculated by collapsing across the two raters. These values were used to calculate descriptive statistics for the daily encounter card and O-EDShOT, including means, standard deviations, and item total correlations. Cronbach's alpha was then calculated for both the daily encounter card and O-EDShOT to investigate the internal consistency of CCERR items across the two workplace-based assessment forms. Generally speaking, acceptable values of alpha range from 0.70 to 0.95 , with $\alpha>0.90$ typically demonstrating excellent internal consistency [24].

To compare the quality of documented assessments on the two workplace-based assessment forms, paired sample $t$ tests were used to determine whether mean CCERR scores, collapsed across raters, differed between daily encounter cards and O-EDShOTs. The analysis was repeated with A-CCERR scores to determine if lack of blinding influenced the results. Data were tested for normality using the Shapiro-Wilk test. To determine whether there were any differences between CCERR item ratings across the two assessment forms, we conducted a repeated-measures analysis of variance (ANOVA), using the mean CCERR scores as the dependent variable and workplace-based assessment form ( 2 levels: daily encounter card vs. O-EDShOT) and mean CCERR item rating (9 levels: 9 CCERR items) as independent variables. Bonferroni corrections were applied to all multiple pairwise comparisons. Effect sizes were calculated using partial eta-squared $\left(\eta^{2}\right)$ for ANOVAs and Cohen $\mathrm{d}$ for $t$ tests. The magnitude of these effect sizes was interpreted using classifications proposed by Cohen: small effect sizes $\approx \eta^{2}<0.02$ and Cohen $d<0.2$; medium effect sizes $\approx 0.02<\eta^{2}<0.13$, and $0.2<d<0.8$; and large effect sizes $\approx \eta^{2}>0.14$ and $d>0.8[23]$.

\section{Results}

There was good interrater reliability for mean CCERR scores between the two raters for both the daily encounter card $($ ICC $(95 \%$ confidence interval $)=0.85(0.69-0.93))$ and moderate interrater reliability for the O-EDShOT (0.74 (0.48-0.88)). Cronbach's alpha revealed high internal consistency of CCERR items for both the daily encounter card and the O-EDShOT ( $\alpha=0.90$ and 0.81 , respectively). CCERR scores were normally distributed for both assessment forms (Shapiro-Wilk for daily encounter card: $W(24)=0.98, p=0.92$; for O-EDShOT: $W(24)=0.95$, $p=0.27)$. Mean CCERR scores were significantly higher for the O-EDShOT $(\operatorname{mean}(\mathrm{SD})=25.6(2.6))$ compared to

Table 1 Mean (SD) and item total correlations (ITC) for CCERR items across daily encounter card and O-EDShOT assessment forms

\begin{tabular}{|c|c|c|c|c|}
\hline \multirow[t]{2}{*}{ CCERR item } & \multicolumn{2}{|l|}{ DEC } & \multicolumn{2}{|l|}{ O-EDShOT } \\
\hline & Mean (SD) & ITC & Mean (SD) & ITC \\
\hline $\begin{array}{l}\text { 1. Checklist/numeric ratings show sufficient variability to allow identification of relative strengths and } \\
\text { weaknesses of the trainee }^{\mathrm{a}}\end{array}$ & $2.3(0.7)$ & 0.6 & $3.0(0.3)$ & 0.3 \\
\hline 2. Comments are balanced providing both strengths and areas for improvement & $2.7(0.5)$ & 0.8 & $2.9(0.4)$ & 0.8 \\
\hline $\begin{array}{l}\text { 3. The trainee's response to feedback and/or remediation during the shift or rotation is described in the } \\
\text { comments }\end{array}$ & $1.1(0.2)$ & 0.5 & $1.0(0.2)$ & 0.3 \\
\hline 4. Comments justify the ratings provided ${ }^{\mathrm{a}}$ & $2.3(0.4)$ & 0.7 & $2.9(0.4)$ & 0.7 \\
\hline $\begin{array}{l}\text { 5. Clearly explained examples of strengths using specific descriptions (not generalizations) are provided in } \\
\text { the comments }\end{array}$ & $2.5(0.7)$ & 0.7 & $2.9(0.8)$ & 0.5 \\
\hline $\begin{array}{l}\text { 6. Clearly explained examples of weaknesses using specific descriptions (not generalizations) are provided } \\
\text { in the comments }\end{array}$ & $2.2(0.7)$ & 0.8 & $2.6(0.6)$ & 0.5 \\
\hline 7. Concrete recommendations for the trainee to attain a higher level of performance are provided & $2.6(0.6)$ & 0.8 & $2.9(0.6)$ & 0.7 \\
\hline 8. Comments are provided in a supportive manner & $2.9(0.2)$ & 0.6 & $3.1(0.2)$ & 0.5 \\
\hline $\begin{array}{l}\text { 9. Overall, this assessment provides enough detail for an independent reviewer to clearly understand the } \\
\text { trainee's performance on the shift }{ }^{\mathrm{a}}\end{array}$ & $2.6(0.5)$ & 0.8 & $3.2(0.3)$ & 0.7 \\
\hline
\end{tabular}

$D E C$ daily encounter card

${ }^{\text {a }}$ Denotes significantly higher $(p<0.05)$ scores for CCERR items 1,4 and 9 for the O-EDShOT as compared to the daily encounter card 
the daily encounter card (21.5(3.9); $t(23)=5.2, p<0.001$, $d=1.1$ ). Similarly, A-CCERR scores were significantly higher for the O-EDShOT (mean $(\mathrm{SD})=18.5(1.6))$ compared with the daily encounter card $(15.5(1.2) ; t(23)=8.4$, $p<0.001$, Cohen's $d=1.7$ ).

Table 1 displays mean (SD) and ITCs for CCERR items. The repeated measures ANOVA demonstrated a significant interaction between workplace-based assessment form and CCERR item, suggesting that the differences between the two assessment forms varied across the individual CCERR items $(F(8,184)=6.40, p<0.001$, $\left.\eta^{2}=0.218\right)$. After correcting for multiple comparisons, ratings for item $1\left(t(23)=4.8, p_{\text {bonferroni }}<0.001, d=0.99\right)$, item $4\left(t(23)=6.7, p_{\text {bonferroni }}<0.001, d=1.36\right)$ and item 9 $\left(t(23)=6.2, p_{\text {bonferroni }}<0.001, d=1.27\right)$ were found to be significantly higher for the O-EDShOT compared to the daily encounter card.

\section{Discussion}

\section{Interpretation of findings}

Our results suggest that faculty provide higher quality documented assessments when using the O-EDShOT compared with the daily encounter card. In competency-based medical education, programs rely heavily on data gathered through workplace-based assessments, and high-quality data is necessary to provide formative feedback and make important decisions about trainee advancement. Previous research on the O-EDShOT has demonstrated its strong psychometric properties; however, this is the first study to demonstrate that the O-EDShOT facilitates higher-quality assessments, which has pragmatic value for driving actionable feedback and for high-stakes decisions about trainee progress and promotion [5, 14, 25]. Our results contribute additional validity evidence for the O-EDShOT at the implications inference stage of Kane's validity framework [26].

\section{Specific factors driving these findings}

Results demonstrated that CCERR items 1, 4 and 9 were rated significantly higher for the O-EDShOT compared to the daily encounter card. These differences likely contributed to the O-EDShOT's overall higher quality. The observed ratings on item 1 ("Checklist/numeric ratings show sufficient variability") indicate that faculty were more likely to use the entire scale when completing the O-EDShOT. A common threat to the validity of workplace-based assessments that use traditional anchors, such as the daily encounter card, is range restriction effects $[8,12-16,27,28]$; in other words, the tendency to rate aspects of a trainee's performance in a narrow range of the scale provided, making it difficult to discern strengths and weaknesses [8, 29, 30]. Our findings align with the existing literature and demonstrate that assessors make greater use of the full scale when tools incorporate entrustment-type anchors such as those used in the O-EDShOT, compared to tools that use traditional anchors $[8,27,28]$. This may also explain why item 4 ("Comments justify the ratings") also demonstrated significantly higher CCERR scores for the O-EDShOT. Previous studies have demonstrated that faculty and trainees perceive the behavioural anchors of the O-EDShOT scale to more accurately represent assessors' day-to-day judgments of performance based on the degree of supervision required $[5,14,16$, 25]. This facilitates more discriminating ratings leading to greater alignment with the narrative comments and identification of strengths and areas for improvement. When ratings and comments are congruent, feedback is perceived as more meaningful and credible to the trainee, while also contributing important data for high-stakes progress and promotions decisions made by the competence committee $[13,15,16$, 31, 32].

We also observed significantly higher scores on CCERR item 9 for O-EDShOTs. Item 9 asks the rater whether the “... assessment provides enough detail for an independent reviewer to clearly understand the trainee's performance on the shift", and essentially represents a gestalt utility judgment of the completed assessment. Our finding that item 9 demonstrated higher mean scores for the O-EDShOT compared to the daily encounter card further supports that not only is the quality of the O-EDShOT superior, but the O-EDShOT also seems to offer greater utility as an assessment tool for capturing trainee on-shift performance.

\section{Clinical implications of findings}

The CCERR provides a quantitative measure of the degree to which a completed workplace-based assessment provides numeric ratings that adequately capture performance as well as narrative comments that are specific, detailed, and use concrete examples [17]. Context-rich narratives of performance and ratings that discriminate between a trainee's strengths and areas for improvement are important springboards for actionable feedback for learning [33, 34]. Additionally, they are critical for contributing meaningful data to the larger system of assessment used by competence committees $[3,4,35]$. Therefore, our findings suggest that the O-EDShOT produces higher-quality assessments compared to the daily encounter card. While prior studies have demonstrated the strong psychometric properties of the O-EDShOT, this study suggests that the O-EDShOT provides better quality assessments [5].

With the implementation of competency-based medical education in Canada, emergency medicine (EM) programs have shifted to a workplace system of assessment 
largely centred around Entrustable Professional Activities (EPAs)-discrete tasks of the discipline [38]. Despite this shift, there remains an important role for assessments of performance over the entire shift. Critics of EPAs argue that deconstructing physician competence into discrete tasks is overly reductionist and may not capture the learner's ability to simultaneously integrate multiple competencies in realworld practice [39, 40]. While the collection of EPAs in the EM transition to practice stage of training attempt to assess higher-level competencies, they still represent discrete tasks (e.g., managing ED flow, supervising learners) that are assessed independently [41]. Furthermore, with the implementation of EPAs, there have been increasing reports of residents and faculty "gaming the system" by selectively completing EPA assessments that are perceived more favorable for progress or to avoid negative feedback, thus threatening the authenticity and validity of those results [42-47]. These concerns point to an ongoing need for a holistic method of assessing performance over an entire shift. The ED shift is the unit of work of an emergency physician. The pragmatic outcome of EM training is to produce physicians who can safely run an ED shift. The O-EDShOT provides a measure of a resident's readiness to do so by assessing the integration and application of multiple competencies over the entire shift. This study and our prior work provide multiple sources of validity evidence for the use of the O-EDShOT which may offer complimentary performance data to the existing EM EPA system of assessment [5].

\section{Strengths, limitations and future directions}

A strength of this study was the use of the A-CCERR to examine the effects of lack of blinding. Our raters could not be blinded to the workplace-based assessment tools while using the CCERR. The A-CCERR does not require raters for scoring, obviating the need for blinding [21]. Notably, the O-EDShOT demonstrated significantly higher mean CCERR and A-CCERR scores, suggesting that the inability to blind CCERR raters did not bias our results [21, 36, 37].

The major limitation of this study is that it was conducted at a single centre. Different institutions likely have unique assessment cultures, and as such, the findings of this study may not be transferable across different training programs. Therefore, we intend to conduct a multicenter implementation study of the O-EDShOT to collect additional validity evidence across training programs with varying assessment systems and cultures.

\section{Conclusion}

The O-EDShOT produces higher-quality assessments compared to the traditional end-of-shift daily encounter card as measured by the CCERR. It offers the potential for greater utility as an assessment tool for capturing trainee on-shift performance that can be used as a stimulus for actionable feedback and a source for high-quality workplace-based assessment data to inform decisions about EM trainee progress and promotion.

Acknowledgements The authors would like to thank Drs. Sebastian Dewhirst and Jeffrey Landreville at the University of Ottawa Department of Emergency Medicine for their contribution as raters in this study, in addition to Katherine Scowcroft, a research assistant at the University of Ottawa Department of Innovation and Medical Education for her support.

Funding This research was supported through grants to the authors from the University of Ottawa Department of Emergency Medicine (DEM) Spring Academic Grant as well as the Medical Student Education Research Grant (MSERG) through the Ontario Medical Students Association (OMSA).

\section{Compliance with ethical standards}

Conflict of interest The authors declare that they have no conflict of interest.

\section{References}

1. Norcini J, Burch V, Norcini J, Burch V. Workplace-based assessment as an educational tool: AMEE Guide No. 31. Med Teach. 2009;31:142-59.

2. Cheung WJ, Dudek N, Wood TJ, Frank JR. Daily encounter cards - evaluating the quality of documented assessments. J Grad Med Educ. 2016;8:601-4.

3. Holmboe ES, Sherbino J, Long DM, Swing SR, Jason R. The role of assessment in competency-based medical education. Med Teach. 2010;32:676-82.

4. Iobst WF, Sherbino J, Cate OT, Richardson DL, Dath D, Swing $\mathrm{SR}$, et al. Competency-based medical education in postgraduate medical education Competency-based medical education in postgraduate medical education. Med Teach. 2010;32:651-6.

5. Cheung WJ, Wood T, Gofton W, Dewhirst S, Dudek N. The Ottawa Emergency Department Shift Observation Tool (O-EDShOT): a new tool for assessing resident competence in the emergency department. AEM Educ Train. 2020;4(4):359-68.

6. Sherbino J, Kulasegaram K, Worster A, Norman GR. The reliability of encounter cards to assess the CanMEDS roles. Adv Heal Sci Educ. 2013;18:987-96.

7. Sherbino J, Bandiera G, Frank JR. Assessing competence in emergency medicine trainees: an overview of effective methodologies. Can J Emeg Med. 2008;10(4):365-71.

8. Bandiera G, Lendrum D. Daily encounter cards facilitate competency-based feedback while leniency bias persists. Can J Emerg Med. 2008;10(1):44-50.

9. Kogan J, Holmboe E, Hauer K. Tools for direct observation and assessment a systematic review. J Am Med Assoc. 2009;302(12):1316-26.

10. Canadian Association of Emergency Physicians. Position statement on emergency medicine definitions from the Canadian Association of Emergency Physicians. 2015

11. American College of Emergency Physicians. Definition of emergency medicine. TX: Irving; 2015. 
12. Crossley J, Johnson G, Booth J, Wade W. Good questions, good answers: construct alignment improves the performance of workplace-based assessment scales. Med Educ. 2011;45:560-9.

13. Dudek N, Gofton W, Rekman J. Faculty and resident perspectives on using entrustment anchors for workplace-based assessment. J Grad Med Educ. 2019;11:287-94.

14. Rekman J, Hamstra SJ, Dudek N, Wood T, Seabrook C, Gofton W. A new instrument for asessing resident competence in surgical clinic: The Ottawa Clinic Assessment Tool. J Surg Educ. 2016;73(4):575-82.

15. Dolan BM, Brien CL, Green MM. Including entrustment language in an assessment form may improve constructive feedback for student clinical skills. Med Sci Educ. 2017;27:461-4.

16. Rekman J, Gofton W, Dudek N, Gofton T, Hamstra SJ. Entrustability scales: outlining their usefulness for competency-based clinical assessment. Acad Med. 2016;91(2):186-90.

17. Dudek NL, Marks MB, Wood TJ, Lee AC. Assessing the quality of supervisors' completed clinical evaluation reports. Med Educ. 2008;42:816-22.

18. Dudek NL, Marks MB, Wood TJ, Dojeiji S, Hatala R, Cooke L, et al. Quality evaluation reports: can a faculty development program make a difference? Med Teach. 2012;34(11):725-31.

19. Dudek NL, Marks MB, Bandiera G, White J, Wood TJ. Quality in-training evaluation reports-does feedback drive faculty performance? 2013;88(8):1129-34.

20. Cheung WJ, Dudek NL, Wood TJ, Frank JR. Supervisor-trainee continuity and the quality of work- based assessments. Med Educ. 2017;51:1260-8

21. Bismil R, Dudek NL, Wood TJ. In-training evaluations: developing an automated screening tool to measure report quality. Med Educ. 2014;48:724-32.

22. Stat Trek. Random number generator [Internet]. 2018 [cited 2020 Jan 12]. https://stattrek.com/statistics/random-number-generator. aspx\#error

23. McGraw KO, Wong SP. Forming inferences about some intraclass correlation coefficients. Psychol Methods. 1996;1(1):30-46.

24. Koo TK, Li MY. A guideline of selecting and reporting intraclass correlation coefficients for reliability research. J Chiropr Med. 2016;15(2):155-63.

25. Tavakol M, Dennick R. Making sense of Cronbach's alpha. Int J Med Educ. 2011;2:53-5.

26. Cohen J. The effect size index: d. Statistical power analysis for the behavioral sciences. 2nd ed. Hillsdale: Erlbaum; 1988.

27. Halman S, Rekman J, Wood T, Baird A, Gofton W, Dudek N. Avoid reinventing the wheel: implementation of the Ottawa Clinic Assessment Tool (OCAT) in Internal Medicine. BMC Med Educ. 2018;18(1):1-8.

28. Cook DA, Brydges R, Ginsburg S, Hatala R. A contemporary approach to validity arguments: a practical guide to Kane's framework. Med Educ. 2015;49(6):560-75.

29. Streiner DL, Norman GR, Cairney J. Health measurement scales: a practical guide to their development and use. 5th ed. New York: Oxford University Press; 2008.

30. Govaerts MJ, Schuwirth LW, Muijtjens AM. Workplace-based assessment: effects of rater expertise. Adv Heal Sci Educ. 2011;16:151-65.

31. Cohen GS, Blumberg P, Ryan NC, Sullivan PL. Do final grades reflect written qualitative evaluations of student performance? Teach Learn Med. 1993;5(1):10-5.

32. Speer AJ, Solomon DJ, Ainsworth MA. An innovative evaluation method in an internal medicine clerkship. Acad Med. 1996;71(1):76-8.
33. Watling CJ, Ginsburg S. Assessment, feedback and the alchemy of learning. Med Educ. 2019;53:76-85.

34. Lefroy J, Watling C, Teunissen PW, Brand P. Guidelines: the do's, don'ts and don't knows of feedback for clinical education. Perspect Med Educ. 2015;4:284-99.

35. Journal AI, Halman S, Dudek N, Wood T, Pugh D, Mcaleer S, et al. Direct observation of clinical skills feedback scale: development and validity evidence. Teach Learn Med. 2016;28(4):38594. https://doi.org/10.1080/10401334.2016.1186552.

36. Marcotte L, Egan R, Soleas E, Dalgarno N, Norris M, Smith C. Assessing the quality of feedback to general internal medicine residents in a competency-based environment. Can Med Educ J. 2019;10(4):32-47.

37. Van Der Vleuten C, Schuwirth L, Driessen E, Dijkstra J, Tigelaar $\mathrm{D}$, Baartman $\mathrm{L}$, et al. A model for programmatic assessment fit for purpose. Med Teach. 2012;34:205-14.

38. Sherbino J, Bandiera G, Doyle K, Frank JR, Holroyd BR, Jones $\mathrm{G}$, et al. The competency-based medical education evolution of Canadian emergency medicine specialist training. Can J Emerg Med. 2019;22(1):95-102.

39. Hawkins RE, Welcher CM, Holmboe ES, Kirk LM, Norcini JJ, Simons KB, et al. Implementation of competency-based medical education: are we addressing the concerns and challenges? Med Educ. 2015;49(11):1086-102.

40. Caverzagie KJ, Nousiainen MT, Ferguson PC, ten Cate O, Ross $\mathrm{S}$, Harris KA, et al. Overarching challenges to the implementation of competency-based medical education. Med Teach. 2017;39(6):588-93.

41. Entrustable Professional Activity Guide: Emergency Medicine. Emerg Med Spec Committee EPA Guid Emerg Med Ottawa R Coll Physicians Surg Canada [Internet]. 2017. https://cloudfront .ualberta.ca/-/media/medicine/departments/emergency-medicine/ documents/epa-guide-emergency-med-e.pdf

42. Pinsk M, Karpinski J, Carlisle E. Introduction of competence by design to Canadian nephrology postgraduate training. Can J Kidney Heal Dis. 2018;5:1-9.

43. Shalhoub J, Marshall DC, Ippolito K. Perspectives on procedurebased assessments: A thematic analysis of semistructured interviews with 10 UK surgical trainees. BMJ Open. 2017;7(3):1-8.

44. Oswald A, Cheung W, Bhanji F, Ladhani M, Hamilton J. Mock Competence Committee Cases. [Internet]. 2020 [cited 2020 May 28]. https://www.royalcollege.ca/mssites/casescenarios_en/story _html5.html

45. LaDonna KA, Hatala R, Lingard L, Voyer S, Watling C. Staging a performance: Learners' perceptions about direct observation during residency. Med Educ. 2017;51(5):498-510.

46. Bindal T, Wall D, Goodyear HM. Trainee doctors' views on workplace-based assessments: are they just a tick box exercise? Med Teach. 2011;33(11):919-27.

47. Martin L, Sibbald M, Brandt Vegas D, Russell D, Govaerts M. The impact of entrustment assessments on feedback and learning: trainee perspectives. Med Educ. 2020;54(4):328-36.

48. Macewan MJ, Dudek NL, Wood TJ, Gofton WT. Continued validation of the O-SCORE (Ottawa Surgical Competency Operating Room Evaluation): use in the simulated environment. Teach Learn Med. 2016;28(1):72-9.

49. Voduc N, Dudek N, Parker CM, Sharma KB, Wood TJ. Development and validation of a bronchoscopy competence assessment tool in a clinical setting. An Am Thorac Soc. 2016;13(4):495-501. 